\title{
Karate in children with neurodevelopmental disorders: an exploratory study
}

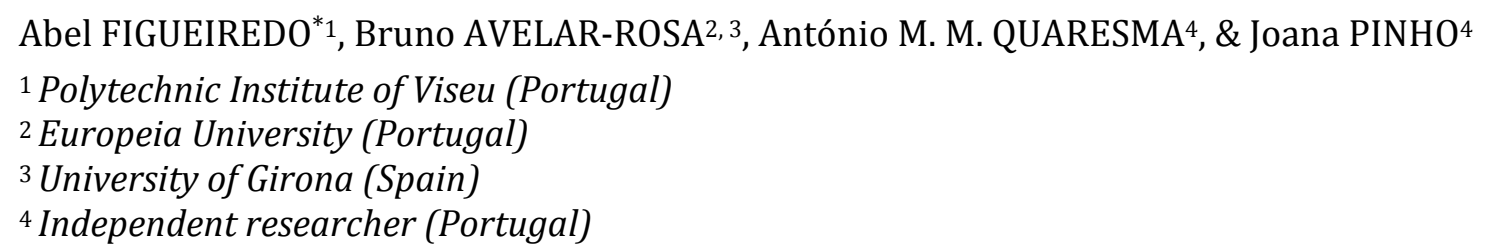

\section{Introduction}

The Neurodevelopment Disorders (ND) are a heterogeneous group of diseases that are based on neurological or sensory permanent abnormalities. Overall, it affects 10 to $20 \%$ of the paediatric population (Lima, 2015; Oliveira, et al., 2012). Among the different sports practices, Martial Arts and Combat Sports (MA\&CS) have interesting features for intervention among the population with this type of special needs. Similarly, studies have been done with the use of karate training and the results seem to have a significant influence on these children (Graham, 2007; Conant, Morgan, Muzykewicz, Clark, \& Thiele, 2008; Woodward, 2009; Bahrami, Mavahedi, Marandi, \& Abedi, 2015). The evidence about the benefits of MA\&CS in general and Karate in particular parallel in the institutional effort carried out by the organizations responsible for sport at the international level but also in different national contexts. Recently, the World Karate Federation created its own Department called "Karate for Disabled".

The objective of this study was to analyse: "peer relationship problems" and "prosocial behaviour" of the Strengths and Difficulties Questionnaire (SDQ); and, "Defiant/Aggressive Behaviours", "Oppositional Defiant Disorder" and DSM-IV-Total of Conners Scale; through an intervention focused on karate classes for children with ND.

\section{Methodology}

Sample was comprised of eight children, aged between 7 and 12 years $(M=8.50 \pm 1.60 ; 7$ boys and 1 girl). All children are diagnosed with ND, ranging from Asperger's Syndrome and Attentiondeficit/hyperactivity disorder (AS\&ADHD) (12.5\%), ADHD (12.5\%), Autism Spectrum Disorders (ASD) (37.5\%), ASD and Specific Language Impairment (SLI) (12.5\%), ASD and ADHD (12.5\%) and a child with a pending diagnose.

Practice time ranges from 6 to 18 months (mean $=11.00 \pm 5.01$ ) with training sessions once a week between 30 to 45 minutes in mode 1 X 1 (75\%) and 1 X 2 (25\%). The intervention focuses on karate lessons that besides the practical component also have a therapeutic component.

To assess and identify specific behavioural problems of this population were used two questionnaires: Conners Scale for parents - revised version (full) (Conners, 1997) and SDQ (Goodman, 1997). Data were collected from baseline and after six months. Statistical analyses were performed using SPSS version 21 software. Descriptive analyses were performed to characterize the sample and comparative nonparametric test (Wilcoxon signed-rank test) were used to compare the evolution from baseline. 


\section{Results}

The average of SDQ dimension "peer relationship problems" was on baseline 7.86 - above the limit (4 to 10) - descending in the second assessment to an average of $5.14(\mathrm{~T}=21 ; p=0.027)$. Also, in the "prosocial behaviour" dimension, there was an evolution from 2,43 - above the limit (0 to 4 ) - to 5.57 ( $\mathrm{T}=28 ; p=0.018$ ), classified as normal (6 to 10 ).

On the other hand, the dimensions of Conners increased from 66.88 (Oppositional Defiant), 76.25 (DSM IV - total) and 75 (Defiant/Aggressive) to $59.75(\mathrm{~T}=21 ; \mathrm{p}=0.027), 70.88(\mathrm{~T}=28 ; \mathrm{p}=0.018$ ) and $67.5(\mathrm{~T}=28 ; \mathrm{p}=0.018)$, respectively (values below 65 are considered normal).

\section{Discussion and conclusion}

There was a significant increase in the variables analysed. Regarding Conners scale, data obtained in dimension "DSM IV - Total" allow us to realize that through Karate significant results were obtained in this population. Decreased visible presentation of common signals in children with ADHD and reduction of behaviours identified as "inattention" and/or "opposition" were observed. Furthermore, "peer relationship problems" decreased and "prosocial behaviour" improved. Our results suggest that Karate can contribute to the therapeutic process of children with PND. Although the literature does not provide sufficient evidence to conclude with greater certainty the positive impact of Karate in special populations, our study shows a trend that should be explored and deepened.

\section{References}

Bahrami, F., Movahedi, A., Marandi, S. M., \& Sorensen, C. (2015). The Effect of Karate Techniques Training on Communication Deficit of Children with Autism Spectrum Disorders. Journal of Autism and Developmental Disorders, 46(3), 978-86.

Conant, K.D., Morgan, A.K., Muzykewicz, D.; Clark, D.C. \& Thiele, EA. (2008). A karate program for improving self-concept and quality of life in childhood. epilepsy: Results of a pilot study. Epilepsy \& Behaviour, 12(1), 61-5.

Goodman, R. (1997). The Strengths and Difficulties Questionnaire: a research note. Journal of child psychology and psychiatry, 38(5), 581-586.

Graham, L.G. (2007). Traditional martial arts and children with ADHD: Self-perceptions of competence. PhD Thesis. Greensboro: Faculty of the Graduate School, University of North Carolina.

Lima, C. B. (2015). Perturbações do Neurodesenvolvimento - Manual de intervenções diagnósticas e estratégias de intervenção. Lisboa: Lidel Editora.

Oliveira, G., Duque, F., Duarte, C.; Melo, F., Teles, T., Brito, M., Vale, M.C., Guimarães, M. J., \& Gouveia, R. (2012). Pediatria do Neurodesenvolvimento. Levantamento nacional de recursos e necessidades. Acta Pediátrica Portuguesa, 43(1), 1-7.

Woodward, T.W. (2009). A review of the Effects of Martial arts practice on Health. Wisconsin Medical Journal, 108(1), 40-43.

Key words: Adapted sport; Karate; martial arts; combat sports; neurodevelopment perturbations; autism. 